\title{
Wearable Antenna for Time-Domain Breast Tumor Detection
}

\author{
Yusnita Rahayu ${ }^{1 *}$, Rosdiansyah ${ }^{1}$, M.F. Hilmi ${ }^{1}$, T. Odih ${ }^{2}$ \\ ${ }^{1}$ Department of Electrical Engineering, Faculty of Engineering, Universitas Riau, Pekanbaru, Riau 28292, \\ Indonesia \\ ${ }^{2}$ Faculty of Medical, Universitas Riau, Pekanbaru, Riau 28292, Indonesia
}

\begin{abstract}
There is a considerable year by year increase in the number of women suffering from breast cancer. Early diagnosis is important to ensure the survival of patients. This study presents the development of a novel, wearable and flexible multiple input multiple output (MIMO) $2 \times 4$ antenna design, which operates at a frequency of 5.5-7 GHz for time-domain breast tumor detection. The antennas are all located in the cup of a bra, which is divided into four quadrants; each quadrant has two antennas for tumor detection. The parameters S11 and S21 for each antenna were measured in the frequency domain. The measured results of S11 and S21 indicate that the antennas worked well both with and without a breast phantom model at the assigned frequency. For antenna five, located in the third quadrant (the quadrant with the tumors), the signal response of the antenna on the breast phantom model had a higher amplitude than that without the breast phantom model. The results demonstrate that the antennas worked well for the detection of the tumors.
\end{abstract}

Keywords: Breast cancer; MIMO, Tumor detection; Wearable antenna

\section{Introduction}

Breast cancer is a major cause of an increased death rate among women. Early detection through regular screening improves the chance of recovery from breast cancer (Beura et al., 2015). Digital mammograms are used to detect breast cancer by classifying the mammogram as either normal or abnormal, using the k-Nearest Neighbor (kNN) method (Nusantara et al., 2016). The use of microwave techniques for breast tumor detection has been extensively researched in recent years. Unlike standard X-ray mammography, these techniques offer breast scans that do not use ionizing radiation, do not require breast compression, and can be implemented at a lower cost (Kim et al., 2008; O'Halloran et al., 2010; Alsharif and Kurnaz, 2018). One of the most important components in the microwave techniques used for breast tumor detection is the ultra-wideband (UWB) antenna. The main principle in UWB imaging is to utilize the existing contrast in the dielectric properties of different breast tissues (AlShehri et al., 2011). One of the image reconstruction techniques used to detect tumors is the development of sparse and low-rank compressive sensing (Sholeh et al., 2020).

Electromagnetic radiation emitted to the human body must comply with the rules set by the international commission on non-ionizing radiation protection (ICNIRP). For the general public, the specific absorption rate $[\mathrm{W} / \mathrm{kg}]$ (SAR), in the frequency range from 10 
$\mathrm{GHz}$, has a limit value of $2 \mathrm{~W} / \mathrm{kg}$ (Kumagai et al., 2011). With UWB technology that uses low input power, it is possible to produce SAR values that meet the predetermined standards.

Research conducted by Bahramiabarghouei et al. (2015) designed a flexible $4 \times 4$ microstrip array antenna, using a coplanar waveguide feeder, to detect breast tumors. The antenna was designed to operate at a frequency of 2-4 GHz. In this study, the substrate used was Kapton Polyimide with $\varepsilon_{\mathrm{r}}=3.5$ and a thickness of $0.05 \mathrm{~mm}$, with an antenna size of 20 $\mathrm{mm} \times 20 \mathrm{~mm}$. This antenna has a wide bandwidth (Ultra Wideband) (Bahramiabarghouei et al., 2015). In a study conducted by Afyf et al. (2015), a flexible microstrip antenna was designed, using a coplanar waveguide feeder, for breast cancer application at a frequency of 2-4 GHz. The substrate used was film. This antenna was very thin $(0.125 \mathrm{~mm})$ and of small size at $15 \mathrm{~mm} \times 20 \mathrm{~mm}$. In this study, the antenna worked in the frequency range of $2-4 \mathrm{GHz}$ with a VSWR of 1.069 . The measured bandwidth of $550 \mathrm{MHz}$ was around $3 \mathrm{GHz}$, and the total gain was about $1 \mathrm{~dB}$. The radiation pattern produced by the antenna was directional (Afyf et al., 2015).

Research conducted by Alsharif and Kurnaz (2018) created a new design for a wearable ultra-wideband (UWB) microstrip patch antenna for use in breast cancer detection. The operating frequency of their proposed antenna ranges from $1.6 \mathrm{GHz}$ to $11.2 \mathrm{GHz}$. The antenna consists of a rectangular radiating patch that is fed by a rectangular feed line. This antenna is designed to be part of a wearable device for women, used to detect breast cancer early. To support its wearable properties, $100 \%$ cotton is used as a substrate with a dielectric constant of 1.6, while the transmission and ground component patches consist of copper as a conductive material (Alsharif and Kurnaz, 2018).

In this article, two previous studies were chosen as our references. In the first study (Porter et al., 2013), a time-domain radar was used as the basis for a breast cancer screening system. The system contained a 16 -element multistatic array that operated in the $2-4 \mathrm{GHz}$ range. In the second study (Mukherjee et al., 2019), a novel, experimental time-reversal imaging (TRI) system, based on a passive time reverse mirror (TRM), for breast tumor detection was presented. A significant contribution of the current study was the development of eight antennas that are distributed into four quadrants. Each quadrant has two antennas covering the area of the breast. The chosen antenna positions are based on the most frequently occurring tumors in the breast area. An algorithm was developed that was capable of extracting tumors from total fields in a bistatic radar setup. The antenna geometry is a unique model that is also our novel contribution.

The current study presents the development of a novel wearable and flexible MIMO $2 \times$ 4 antenna design for time-domain breast tumor detection. This article describes the methodology used to detect a tumor in the breast phantom. All antennas were located in the cup of a bra, which was divided into four quadrants; each quadrant had two antennas for tumor detection. The study analyzed the measurement results from the antennas in both frequency and time domains. The antennas were measured using a vector network analyzer (VNA). The S21 represents the power transferred from Port 1 to Port 2 (VNA) and the S11 is the reflected power. The S11 and S21 were measured for each antenna, both with and without a breast phantom.

\section{Methods}

The proposed wearable antenna was designed using a polyethylene (PET) substrate with a thickness of $0.125 \mathrm{~mm}$ and a dielectric constant of 3.0. Figure 1 shows the novel antenna geometry and the prototype that was printed using AgNP ink as the radiating material. The full dimensions of the antenna are shown in Table 1.

The proposed design consists of MIMO $2 \times 4$ flexible antennas with SMA ports operated at a frequency of 5.5-7 GHz. All antennas are located in the cup of the bra, which is divided into four quadrants; each quadrant has two antennas for tumor detection. 


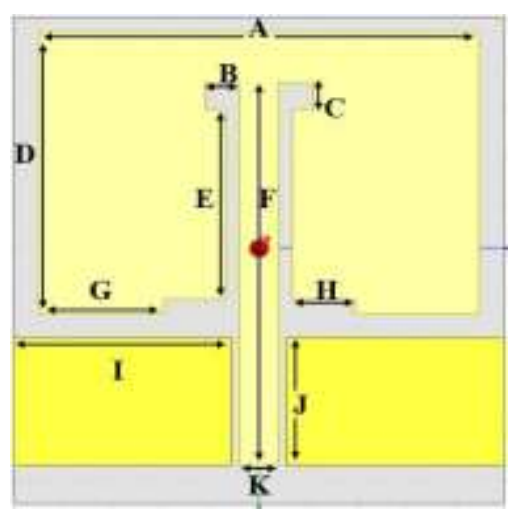

(a)

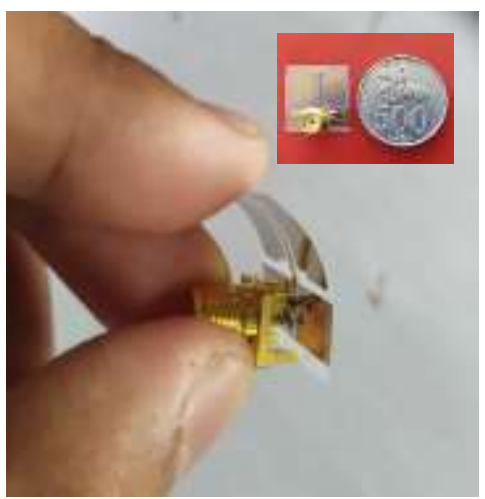

(b)

Figure 1 (a) Antenna geometry; (b) prototype

Table 1 Antenna dimensions

\begin{tabular}{cc}
\hline Parameter & Dimensions $(\mathrm{mm})$ \\
\hline A & 18 \\
B & 1.4 \\
C & 1.15 \\
D & 12.2 \\
E & 8.2 \\
F & 16.5 \\
G & 5.1 \\
H & 2.5 \\
I & 8.9 \\
J & 5.5 \\
K & 1.6 \\
\hline
\end{tabular}

The division of the cup of the bra into four quadrants is a novel technique proposed by the researcher for the implementation of wearable antennas. With this division, two antennas are needed to cover each small area of the breast, so eight antennas are needed to cover the entire breast area. The four areas covered are the areas medically shown to be potential sites for the presence of tumors. In another article, the researcher did not explain how they determined the number of antennas used for the detection of tumors in the breast (Xia et al., 2013, Porter et al., 2013b, Santorelli et al., 2013, Bahramiabarghoue et al., 2015, Kendall et al., 2020)

In this article, the research focuses on how the antennas can detect the presence of tumors by observing the time-domain signals generated. The breast phantom used was readily available and already had three tumors of predefined sizes. The breast phantom used contained three tumors of $5 \mathrm{~mm}$ in size. The tumors were in the third quadrant, which contained antennas numbers 1 and 5 .

In general, tumors arise when there is an overgrowth of cells in tissue, which forms a lump. When the growth of these cells is uncontrolled, the tumor that forms is called a malignant tumor or cancer. Malignant or cancerous tumors are larger than $2 \mathrm{~cm}$. Sizes smaller than $2 \mathrm{~cm}$ are categorized as benign tumors. In a paper by Dummin et al. (2007), the authors report on a study conducted to detect the size of breast tumors that can be identified when using mammography or sonography. The mammography was able to detect a breast tumor as small as $5 \mathrm{~mm}$, and the sonography was able to detect one of $3 \mathrm{~mm}$. In the current study, the tumor size was $5 \mathrm{~mm}$, and it is hoped that, with this small size, the antennas will be able to detect the presence of tumors early. 


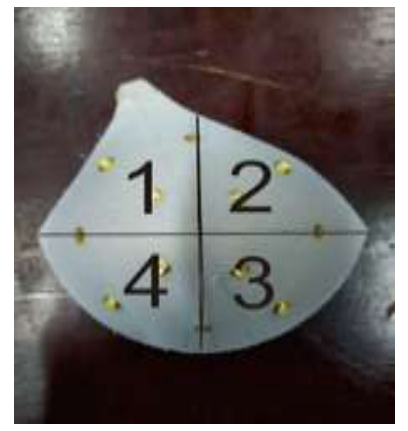

(a)

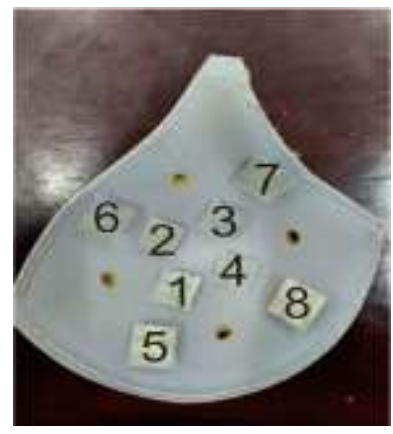

(b)

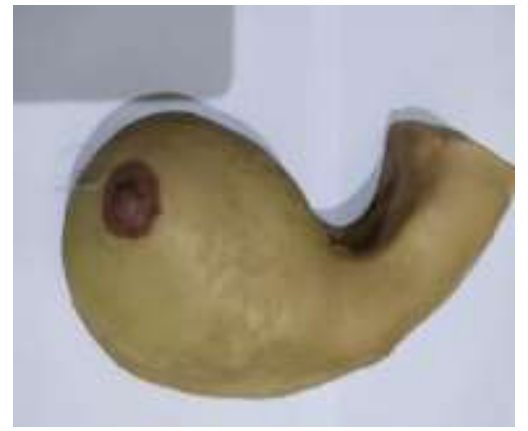

(c)

Figure 2 Placement of the antenna in the cup of the bra: (a) outside display; (b) inner display; and (c) breast phantom model

Figures $2 \mathrm{a}$ and $2 \mathrm{~b}$ show the antenna placement in the cup of the bra. This placement makes the process of tumor detection easier because each quadrant of the phantom breast will be investigated by two antennas. Figure 2c shows the breast phantom model with a tumor. The objective is to detect the tumor using the antennas. The breast phantom is made of silicon, with dacron as the breast tissue. The tumor is made of compacted dacron and placed in the third quadrant of the breast phantom model.

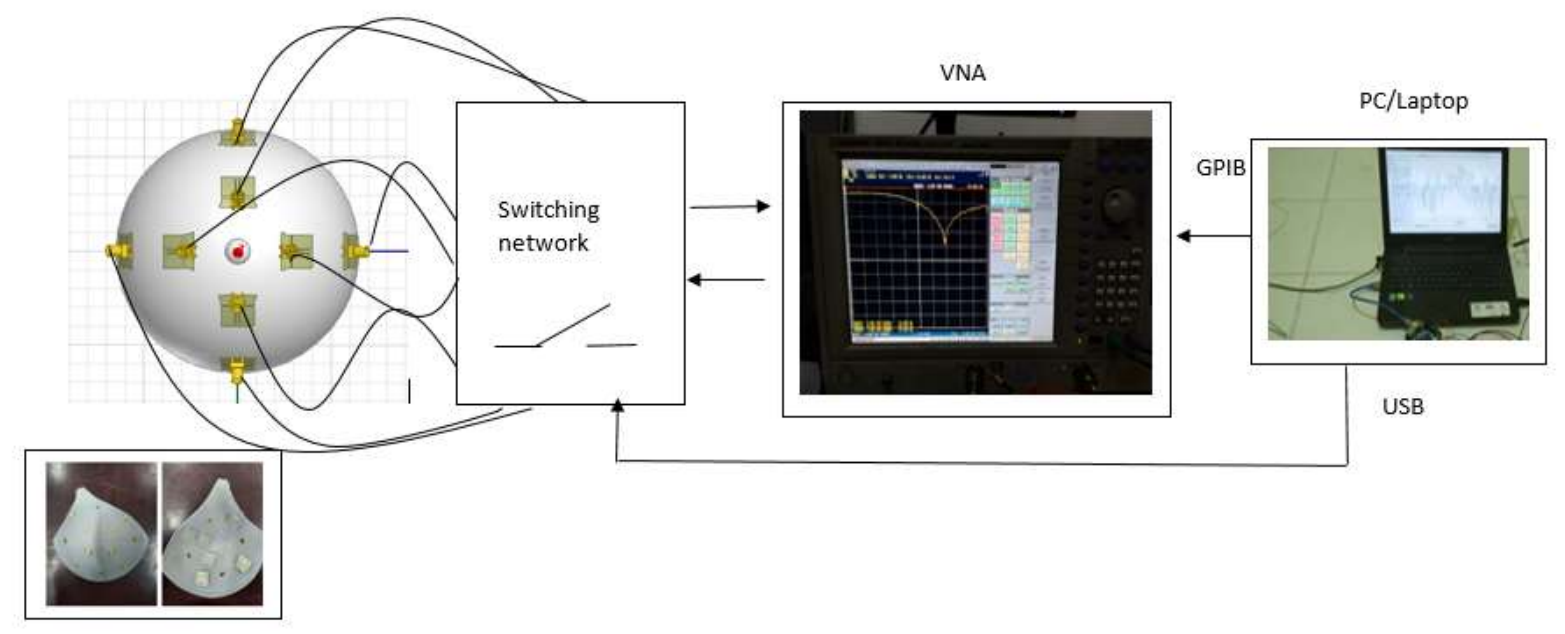

Figure 3 Design showing the complete method used for breast tumor detection

Figure 3 shows the method used for breast tumor detection, in which each port of the element antenna is connected to the switching network and VNA is used to generate signals in the frequency domain. The switching network will detect tumor objects due to being activated from two ports, where one port is the transmitter and the other is the receiver. The receiving antenna will be activated alternately to all quadrants of the breast phantom. The transmission coefficient resulting from the simulation and measurement is in the frequency domain. To transform it to the time domain, Matrix Laboratory (MATLAB) software is used, installed in a computer. The results of the measurement indicate the transfer function that describes the relation between the transmitted signal (STx) and the received signal (SRx). The data obtained from the VNA are then processed and analyzed by MATLAB 2013, providing a detailed image of the breast.

Figure 4 shows the antenna measurement process using the breast phantom model. The parameters S11 and S21 for each port were measured with and without the breast 
phantom model. During the measurement of S21, antenna 1 was used as the antenna transmitter, and the rest of the antennas were used as antenna receivers.

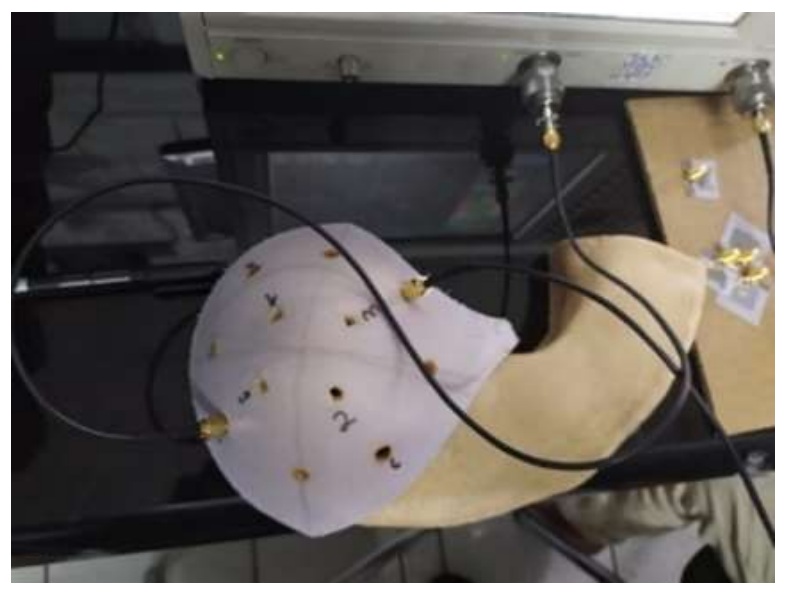

Figure 4 Antenna measurement using a breast phantom model

\section{Results and Discussion}

To validate the proposed scheme, all antennas were measured. The measurement results for all antennas is shown in Figure 5.

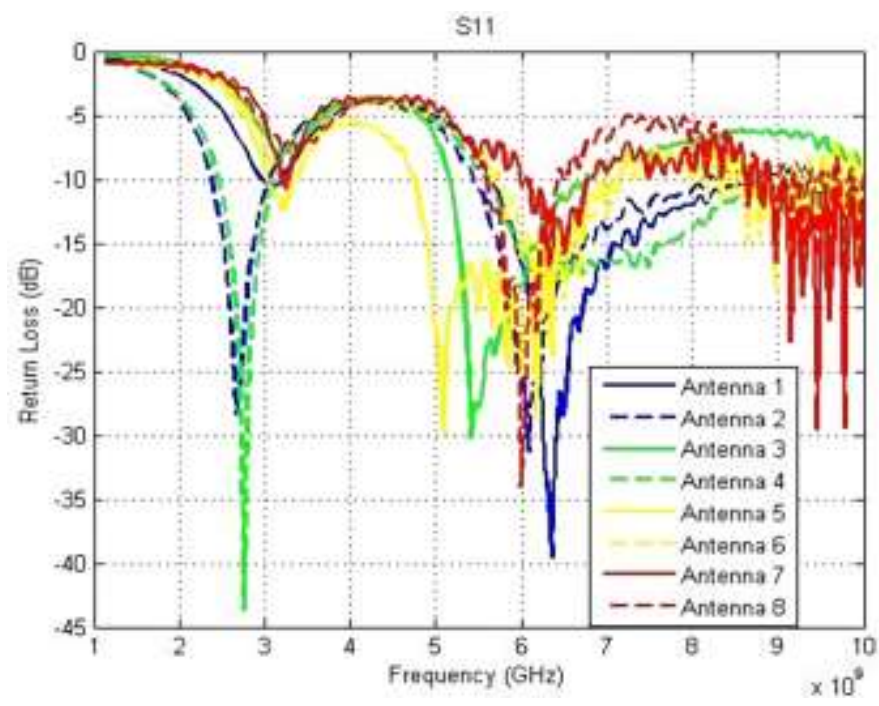

Figure 5 Measured return loss of antennas

Figure 5 shows the measured return loss of the eight antennas with respect to $-10 \mathrm{~dB}$ (without the phantom). Most antennas worked well in the frequency range of 5.5-7 GHz with a bandwidth of more than $500 \mathrm{MHz}$. The observed return loss for each antenna was more than $-25 \mathrm{~dB}$. Each antenna showed a different measured return loss result, which was probably caused by human error during the testing and installing of the connector port on each antenna. Since the antennas are made of PET material, the test must be carried out with care. However, the eight antennas were still able to work in the specified UWB frequency range. We used two schemes to validate the tumor detection method: frequencydomain analysis and time-domain analysis. With UWB technology, the time-domain analysis is necessary to detect a breast tumor by performing an inverse Fourier transform (IFT) calculation. 


\subsection{Analysis of the Antenna Measurement in the Frequency Domain}

The parameters measured for the frequency domain were S11 and S21 for each antenna, both with and without the breast phantom. The S11 measurement was carried out for each antenna to ensure that the antenna had a reflection coefficient value of less than $-10 \mathrm{~dB}$ and was in the UWB frequency range. The S11 results in the frequency domain for antennas in the $1^{\text {st }}$ and $2^{\text {nd }}$ quadrants are shown in Figure 6.

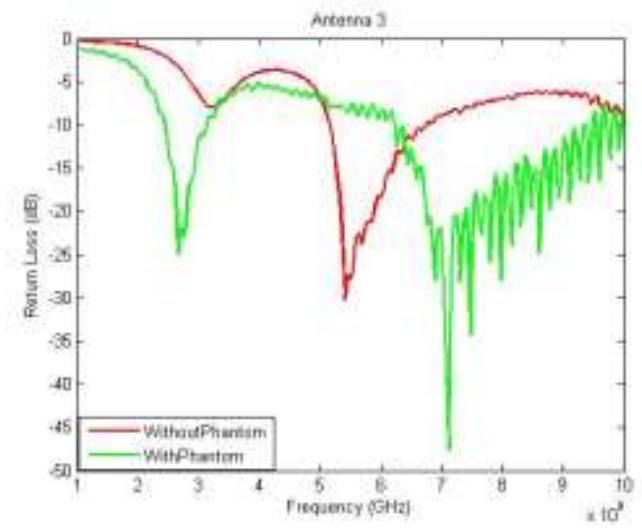

(a)

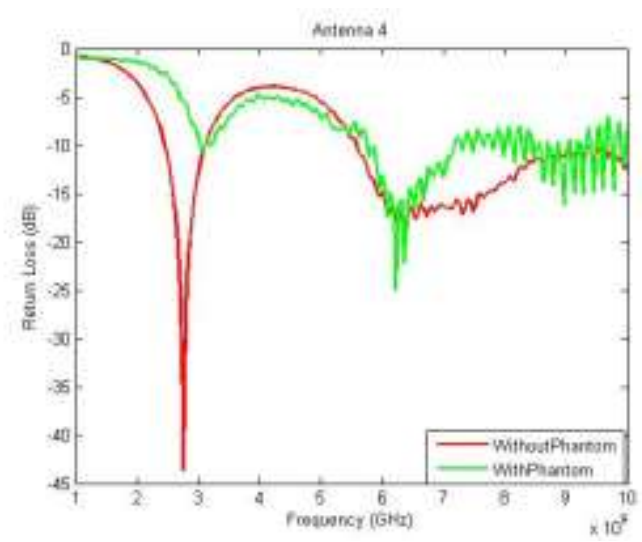

(c)

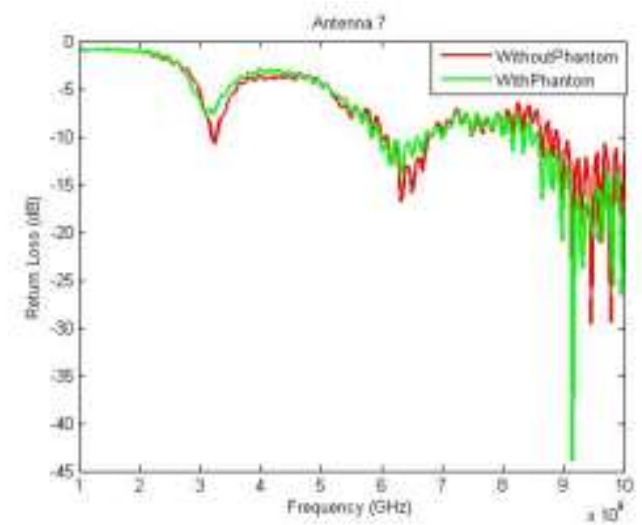

(b)

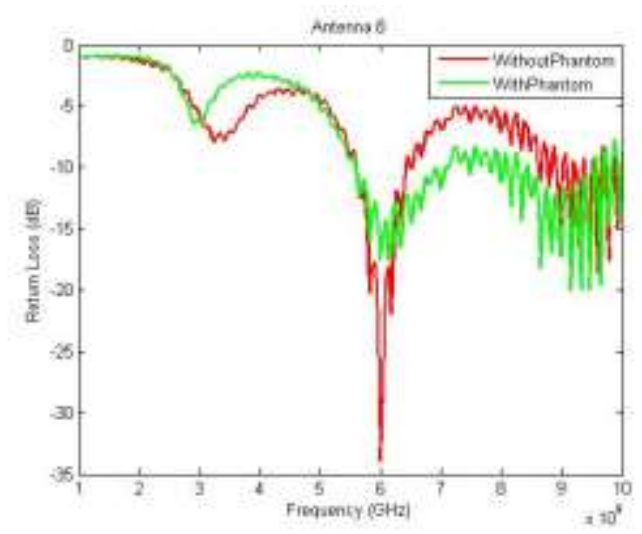

(d)

Figure 6 S11 parameter results from the antennas in the $1^{\text {st }}$ and $2^{\text {nd }}$ quadrants: (a) antenna 3; (b) antenna 7; (c) antenna 4; and (d) antenna 8

The measurement of S11 for each antenna in each quadrant was intended to show whether the working frequency of the antenna experienced a shift when the testing used the breast phantom. This was necessary to ensure that the antennas continued to work in the UWB frequency range. Figure 6 shows the S11 parameter results from the antennas in the $1^{\text {st }}(\mathrm{a}$ and $\mathrm{b})$ and $2^{\text {nd }}(\mathrm{c}$ and $\mathrm{d})$ quadrants of the breast phantom model. The $1^{\text {st }}$ and $2^{\text {nd }}$ quadrants of the breast phantom model did not contain any tumor. The measurements were done and show that some shifts in frequency occurred between the measurements of S11 with and without the breast phantom.

The red line in Figure 6a shows the measured S11 of antenna 3, without the phantom, working in the $5 \mathrm{GHz}$ frequency range. When the phantom was used in the measurement, the frequency shifted to the $7 \mathrm{GHz}$ range. The phantom is thus shown to have affected the operating frequency of antenna 3. Figure $6 \mathrm{~b}$ shows that the measured S11 for antenna 7, with and without the phantom, was similar. The $1^{\text {st }}$ quadrant was opposite the $3^{\text {rd }}$ quadrant, where the tumor was located, and antenna 3 was located nearer to the $3^{\text {rd }}$ quadrant than antenna 7. 
A change in frequency was shown by antenna 4 during the measurement of the $2^{\text {nd }}$ quadrant with and without the phantom. However, antenna 8 showed similar results for both measurements. The $2^{\text {nd }}$ quadrant was next to the $3^{\text {rd }}$ quadrant, and the position of the antenna in each quadrant reflected the differences in the results derived from the S11 measurements and the working frequency. This depended on the distance between each antenna and the position of the tumor in quadrant 3.

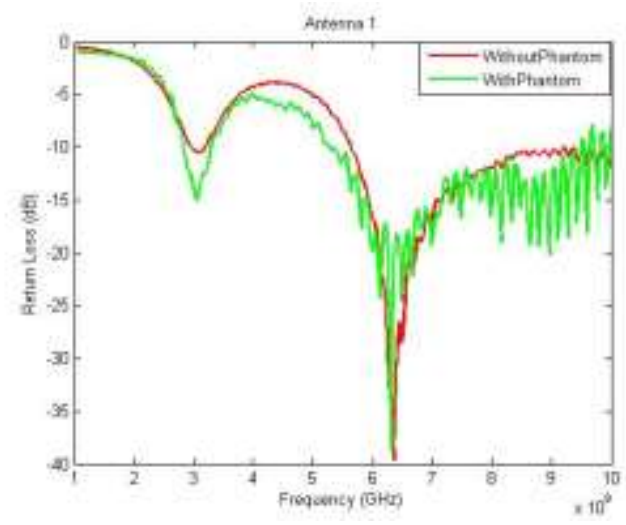

(a)

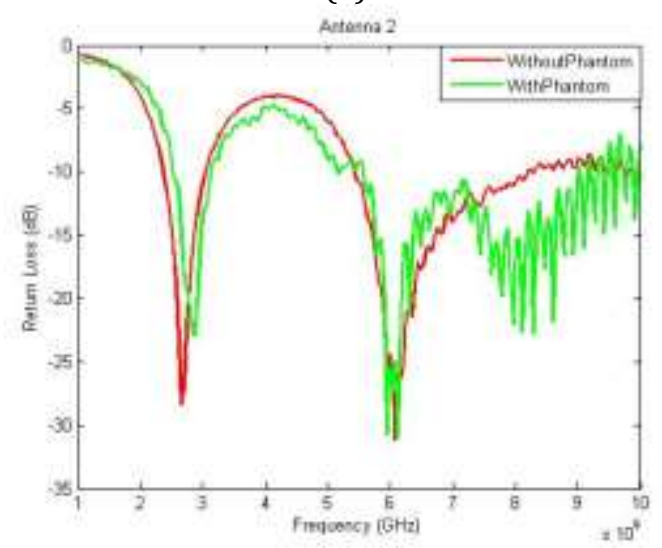

(c)

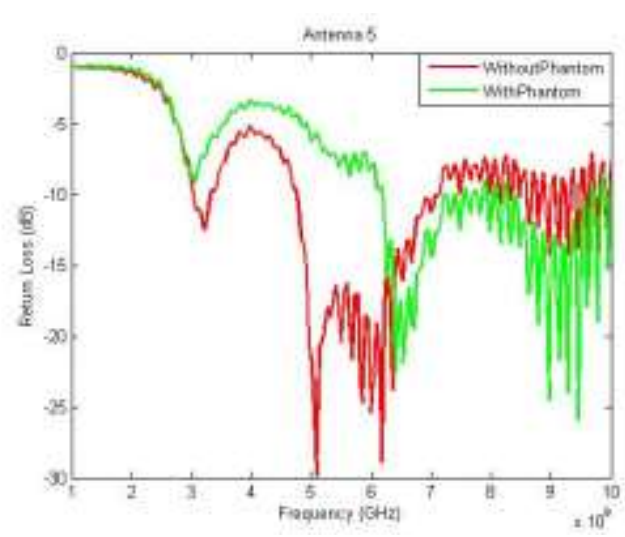

(b)

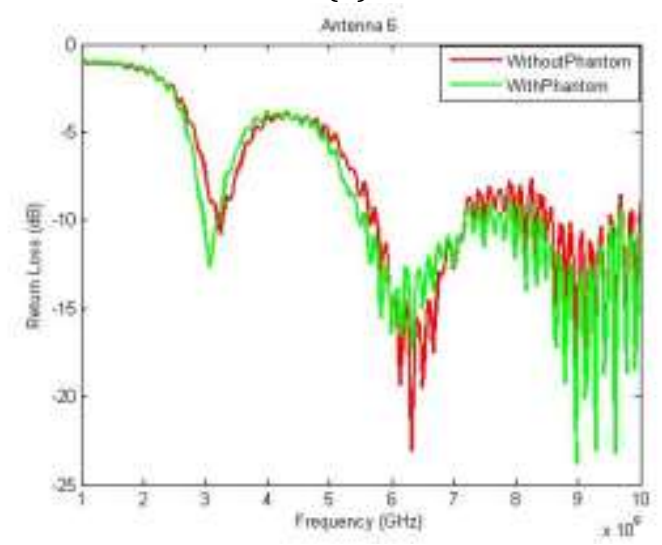

(d)

Figure $7 \mathrm{~S} 11$ parameter results from the antennas in the $3^{\text {rd }}$ and $4^{\text {th }}$ quadrants: (a) antenna 1; (b) antenna 5; (c) antenna 2; and (d) antenna 6

Figure 7 shows the S11 parameter results from the antennas in the $3^{\text {rd }}$ ( $a$ and b) and $4^{\text {th }}$ (c and d) quadrants of the breast phantom model. The $3^{\text {rd }}$ quadrant of the breast phantom model was the quadrant containing three tumors. The operating frequency for antenna 5 shifted to the $6 \mathrm{GHz}$ range when measuring with the phantom. These results indicate that the antennas worked well in detecting the breast tumors.

Next, the detection of the tumors was conducted using the S21 parameters. Figure 8 shows the S21 parameter results from the antennas in the $1^{\text {st }}$ ( $a$ and b) and $2^{\text {nd }}$ (c and d) quadrants of the breast phantom model. The term S21 indicates that antenna 1 is the transmitter and antenna 2 is the receiver. In this situation, only antenna 1 was a transmitter and the others were antenna receivers. For example, Figure 8a shows the S21 for antennas 1 and 3, where antenna 1 was the transmitter and antenna 3 the receiver.

Figure 9 shows the S21 parameter results from the antennas in the $3^{\text {rd }}(\mathrm{a})$ and $4^{\text {th }}(\mathrm{b}$ and c) quadrants of the breast phantom model. Figures 7 and 8 show that the S21 measured with the breast phantom model had a similar pattern to the S21 measured without the 
breast phantom. The green line in Figure 9 shows the S21 measured using the breast phantom, and the red line shows the S21 measured without the breast phantom.

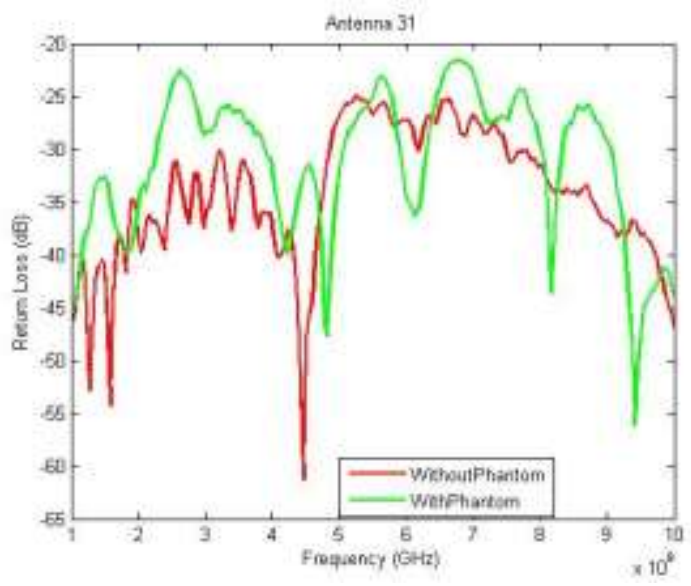

(a)

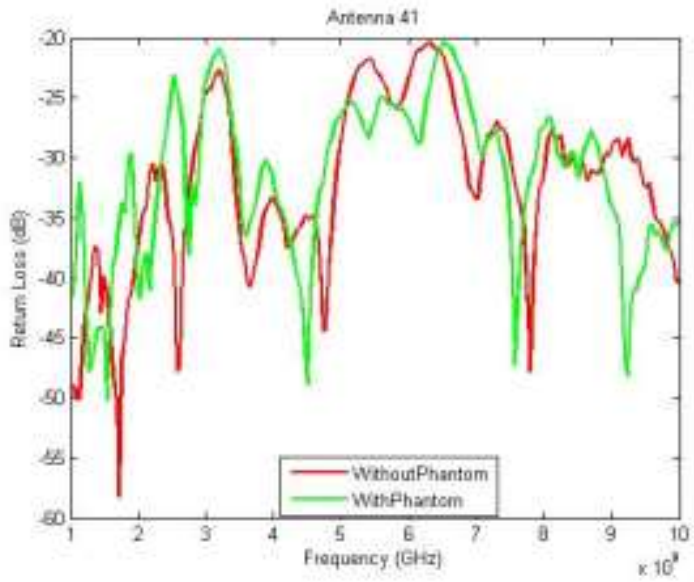

(c)

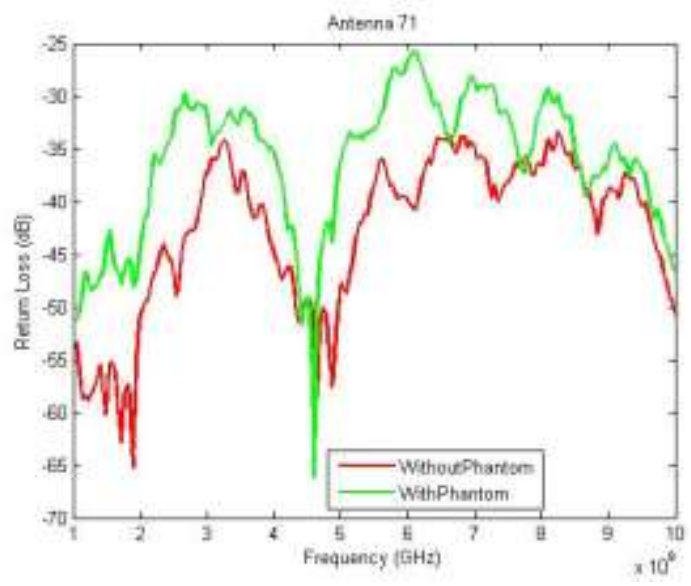

(b)

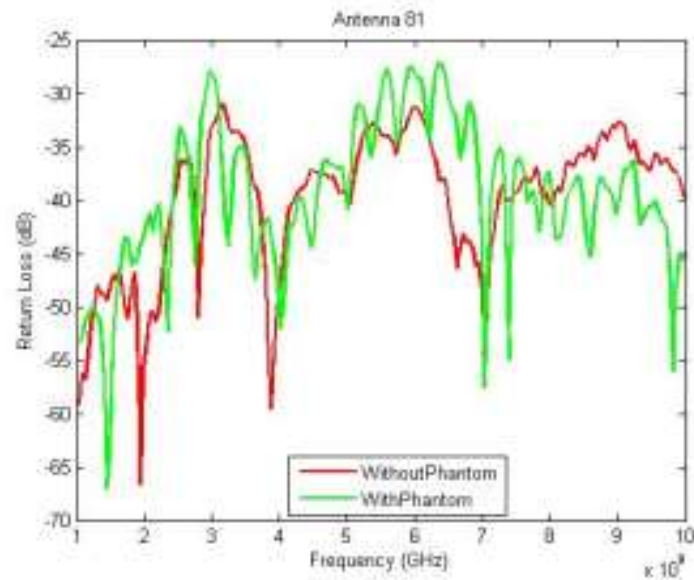

(d)

Figure 8 S21 parameter results from the antennas in $1^{\text {st }}$ and $2^{\text {nd }}$ quadrants: (a) antenna 3-1;

(b) antenna 7-1; (c) antenna 4-1; and (d) antenna 8-1

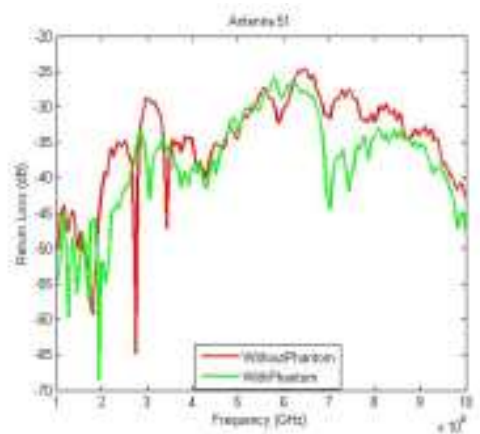

(a)

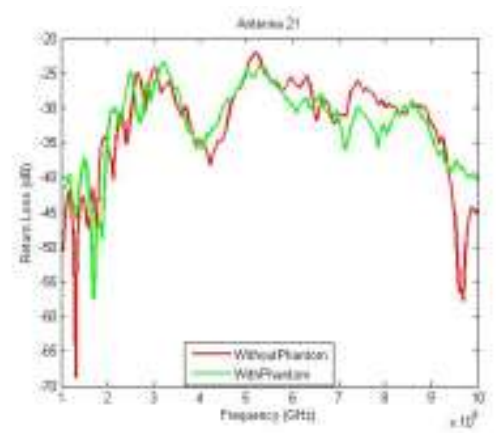

(b)

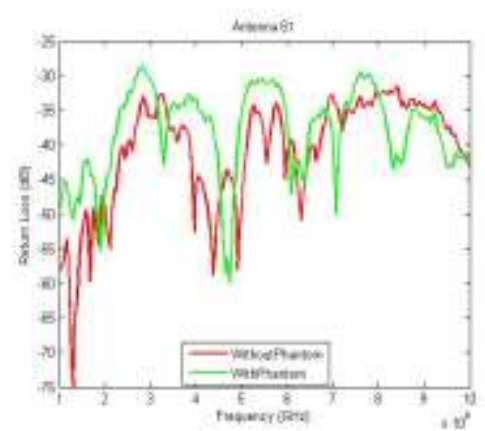

(c)

Figure 9 S21 parameter results from the antennas in the $3^{\text {rd }}$ and $4^{\text {th }}$ quadrants: (a) antenna 5-1; (b) antenna 2-1; and (c) antenna 6-1

\subsection{Analysis of the Antenna Measurement in the Time Domain}

Figure 10 shows the time-domain results for all antennas based on the measurements. All antennas are compared to the transmission coefficient of antenna 1 to antenna 5, because the tumor was located close to antennas 1 and 5 (Quadrant 3). 


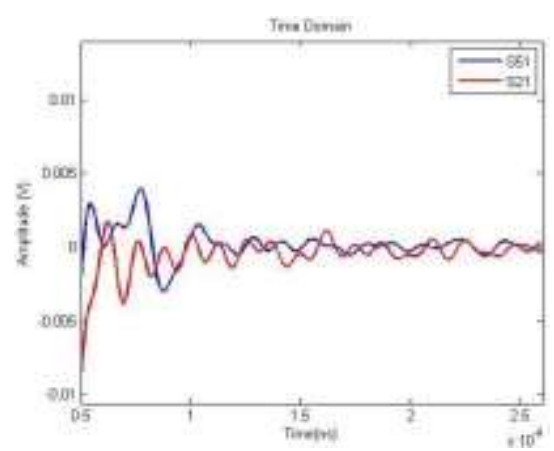

(a)

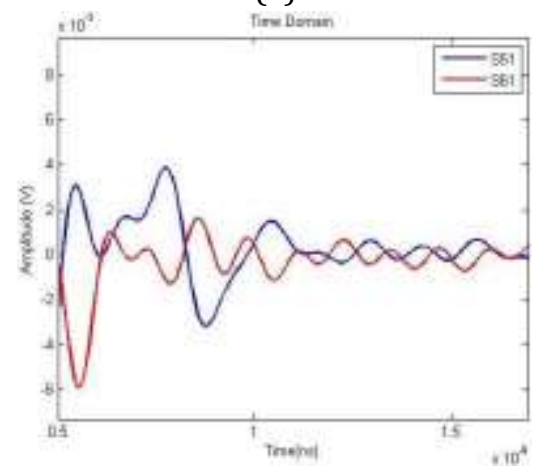

(d)

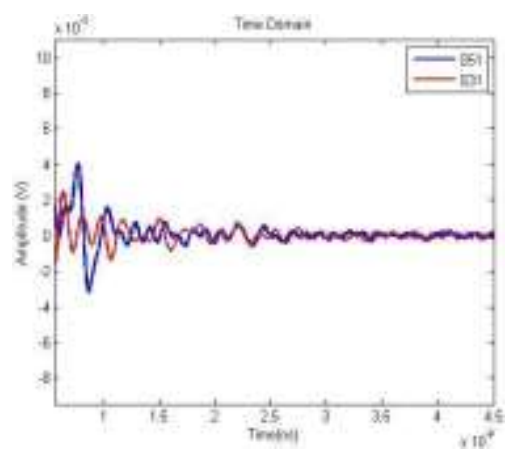

(b)

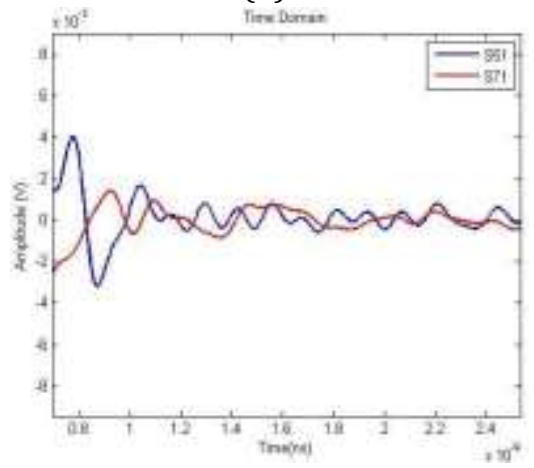

(e)

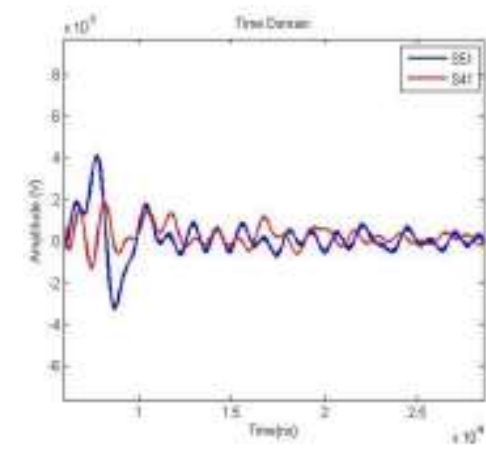

(c)

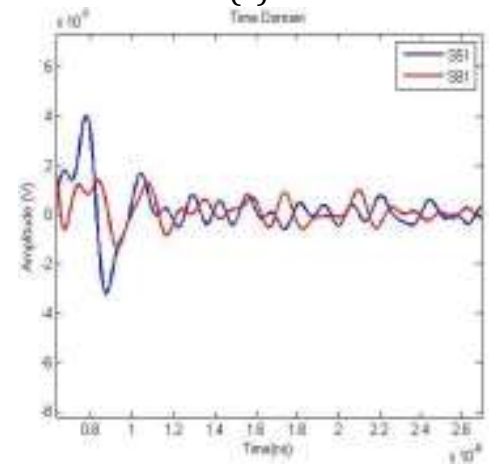

(f)

Figure 10 The time-domain results based on the measurements: (a) S5-1 compared to S2-1; (b) S51 compared to S3-1; (c) S5-1 compared to S4-1; (d) S5-1 compared to S6-1; (e) S5-1 compared to S7-1; (f) S5-1 compared to S8-1

The results show that the antennas in the quadrant with tumors have a higher amplitude than the antennas in quadrants without tumors. This is because the wave is reflected by the tumor to the receiver antenna. These results demonstrate that the antennas have the potential to work well for tumor detection.

\subsection{Comparison of Research Results with Those of Related Studies}

The results of this study were compared with those of several related studies regarding the placement of antennas in detecting the presence of tumors. This comparison was conducted to clarify the contribution of the authors. The research selected all focused on using multiple antennas for this purpose. Table 2 presents the results of the comparison.

Table 2 Comparison of our results with those of prior studies

\begin{tabular}{llcccc}
\hline \multicolumn{1}{c}{ Reference } & Type of antenna & $\begin{array}{c}\text { Number of } \\
\text { antennas used }\end{array}$ & $\begin{array}{c}\text { Position } \\
\text { technique }\end{array}$ & $\begin{array}{c}\text { Time- } \\
\text { domain } \\
\text { analysis }\end{array}$ & $\begin{array}{c}\text { Frequency } \\
(\mathrm{GHz})\end{array}$ \\
\hline $\begin{array}{l}\text { Santorelli et al. } \\
(2013)\end{array}$ & $\begin{array}{l}\text { Traveling wave, } \\
\text { tapered and loaded } \\
\text { transmission line } \\
\text { antenna } \\
\text { (TWTLTLA) }\end{array}$ & 16 & $\begin{array}{c}\text { Hemispherical } \\
\text { radome }\end{array}$ & Yes & $3-12$ \\
& $\begin{array}{l}\text { Traveling wave, } \\
\text { tapered and loaded } \\
\text { transmission line } \\
\text { antenna } \\
\text { (TWTLTLA) }\end{array}$ & 16 & $\begin{array}{l}\text { Hemispherical } \\
\text { bowl-shaped } \\
\text { radome }\end{array}$ & Yes & $2-4$ \\
\hline $\begin{array}{l}\text { Porter et al. } \\
\text { (2013b) }\end{array}$ & Not specified & 9 & $\begin{array}{l}\text { Planar breast } \\
\text { structure }\end{array}$ & Yes \\
\hline Xia et al. (2013) & & & \\
\hline
\end{tabular}




\begin{tabular}{|c|c|c|c|c|c|}
\hline Reference & Type of antenna & $\begin{array}{c}\text { Number of } \\
\text { antennas used }\end{array}$ & $\begin{array}{l}\text { Position } \\
\text { technique }\end{array}$ & $\begin{array}{c}\text { Time- } \\
\text { domain } \\
\text { analysis }\end{array}$ & $\begin{array}{l}\text { Frequency } \\
\quad \text { (GHz) }\end{array}$ \\
\hline $\begin{array}{l}\text { Bahramiabarghouei } \\
\text { et al. (2015) }\end{array}$ & Flexible antenna & 16 & $\begin{array}{l}\text { Single-arm, } \\
\text { spiral antenna } \\
\text { array }\end{array}$ & Yes & $2-4$ \\
\hline Rashid et al. (2019) & $\begin{array}{l}\text { Meandering } \\
\text { monopole } \\
\text { microstrip patch } \\
\text { antenna }\end{array}$ & 4 & $\begin{array}{l}\text { Rectangular } \\
\text { tissue model }\end{array}$ & No & 1.5 \\
\hline $\begin{array}{l}\text { Fortaleza, et al. } \\
(2020)\end{array}$ & UWB antenna & 16 & $\begin{array}{l}\text { Two concentric } \\
\text { rings of eight } \\
\text { antennas }\end{array}$ & No & $2-4$ \\
\hline $\begin{array}{l}\text { Kendall et al. } \\
(2020)\end{array}$ & Flexible antenna & 16 & $\begin{array}{l}\text { Two rings of } \\
\text { eight antennas }\end{array}$ & Yes & $2-4$ \\
\hline $\begin{array}{l}\text { Rahayu et al. (this } \\
\text { study) }\end{array}$ & $\begin{array}{l}\text { Flexible UWB } \\
\text { antenna }\end{array}$ & 8 & $\begin{array}{l}\text { Four quadrants } \\
\text { of bra cup }\end{array}$ & Yes & $5.5-7$ \\
\hline
\end{tabular}

\section{Conclusions}

This study introduces a novel wearable and flexible MIMO $2 \times 4$ antenna design operating at a frequency of 5.5-7 GHz for time-domain breast tumor detection. The parameters S11 and S21 for each antenna, with and without the breast phantom, were measured. The results show that the measurements of S11 and S21 in the frequencies domain were similar. However, in some frequencies, shifts did occur between the measurements of S11 with or without the breast phantom, but these were not significant.

The signal response from the antenna measurements in the quadrant with the breast tumor had a higher amplitude than those measured without a breast tumor. These results indicate that the antennas will work well for tumor detection. In future work, the size and depth of the tumor detected should be explored and evaluated.

\section{Acknowledgements}

This work was financially supported by the Indonesia Ministry of Research, Technology, and Higher Education under the INSINAS Program. The authors would like to thank the Indonesian Science Institute (LIPI) for the use of their measurement facility, and the Research and Community Service Agency (LPPM) Universitas Riau for their motivation and management of the research.

\section{References}

Alsharif, F., Kurnaz, C., 2018. Wearable Microstrip Patch Ultra Wide Band Antenna for Breast Cancer Detection. In: The $41^{\text {st }}$ International Conference on Telecommunications and Signal Processing, TSP 2018

Afyf, A., Bellarbi, L., Errachid, A., Sennouni, M.A., 2015. Flexible Microstrip CPW Slotted Antenna for Breast Cancer Detection. In: The 2015 International Conference on Electrical and Information Technologies (ICEIT), pp. 292-295

AlShehri, S.A., Khatun, S., Jantan, A.B., Abdullah, R.S.A.R., Mahmud, R., Awang, Z., 2011. Experimental Breast Tumor Detection using NN-based UWB Imaging. Progress In Electromagnetics Research, Volume 111, pp. 447-465

Beura, S., Majhi, B., Dash, R., Roy, S., 2015. Classification of Mammograms using TwoDimensional Discrete Orthonormal S-Transform for Breast Cancer Detection. Healthcare Technology Letters, Volume 2(2), pp. 46-51 
Bahramiabarghouei, H., Porter, E., Santorelli, A., Gosselin, B., Popović, M., Rusch, L.A. 2015. Flexible 16 Antenna Array for Microwave Breast Cancer Detection. IEEE Transactions on Biomedical Engineering, Volume 62(10), pp. 2516-2525

Dummin, L.J., Cox, M., Plant, L., 2007. Prediction of Breast Tumor Size by Mammography and Sonography-A Breast Screen Experience. Breast, Volume 16(1), pp. 38-46

Fortaleza, L., Kranold, L., Popović, M., 2020. Flexible 16-Antenna System for Microwave Breast Screening: NB vs. UWB Performance. IEEE International Symposium on Antennas and Propagation and North American Radio Science Meeting, pp. 1289-1290

Kendall, W., Kranold, L., Hahn, C., Studebaker, S., Schwartz, J., Popović, M., 2020. A Flexible Antenna Array with Integrated Switching Matrix for Breast Cancer Detection. In: The $42^{\text {nd }}$ Annual International Conference of the IEEE Engineering in Medicine \& Biology Society (EMBC), pp. 4369-4372

Kim, H., Claffy, K.C., Fomenkov, M., Barman, D., Faloutsos, M., Lee, K.Y., 2008. Internet Traffic Classification Demystified: Myths, Caveats, and the Best Practices. In: Proceedings of 2008 ACM CoNEXT Conference-4th International Conference on Emerging Networking Experiments and Technologies, CoNEXT '08, January

Kumagai, T., Saito, K., Takahashi, M., Ito, K., 2011. A Small 915MHz Receiving Antenna for Wireless Power Transmission Aimed at Medical Applications. International Journal of Technology, Volume 2(1), pp. 20-27

Mukherjee, S., Udpa, L., Udpa, S., Rothwell, E.J., Deng, Y., 2019. A Time Reversal-Based Microwave Imaging System for Detection of Breast Tumors. IEEE Transactions on Microwave Theory and Techniques, Volume 67(5), pp. 2062-2075

Nusantara, A.C., Purwanti, E., Soelistiono, S., 2016. Classification of Digital Mammograms based on Nearest-Neighbor Method for Breast Cancer Detection. International Journal of Technology, Volume 7(1), pp. 71-77

O’Halloran, M., Glavin, M., Jones, E., 2010. Rotating Antenna Microwave Imaging System for Breast Cancer Detection. Progress in Electromagnetics Research, Volume 107, pp. 203217

Porter, E., Kirshin, E., Santorelli, A., Coates, M., Popoví, M., 2013a. Time-domain Multistatic Radar System for Microwave Breast Screening. IEEE Antennas and Wireless Propagation Letters, Volume 12, pp. 229-232

Porter, E., Kirshin, E., Santorelli, A., Popovic, M., 2013b. Microwave Breast Screening in the Time-Domain: Identification and Compensation of Measurement-Induced Uncertainties. Progress In Electromagnetics Research B, Volume 55, pp. 115-130

Rashid, M.M.U., Rahman, A., Paul, L.C., Rafa, J., Podder, B., Sarkar, A.K., 2019. Breast Cancer Detection \& Tumor Localization using Four Flexible Microstrip Patch Antennas. International Conference on Computer, Communication, Chemical, Materials and Electronic Engineering (IC4ME2), pp. 1-6

Santorelli, A., Chudzik, M., Kirshin, E., Porter, E., Lujambio, A., Arnedo, I., Popovic, M., Schwartz, J.D., 2013. Experimental Demonstration of Pulse Shaping for Time-Domain Microwave Breast Imaging. Progress in Electromagnetics Research, Volume 133, pp. 309-329

Sholeh, H.R., Rizkinia, M., Basari, B., 2020. Design of Microwave-based Brain Tumor Detection Framework with the Development of Sparse and Low-Rank Compressive Sensing Image Reconstruction. International Journal of Technology, Volume 11(5), pp. 984-994

Xia, X., Li, X., Qin-Wei, L., 2013. A Double Constrained Robust Capon Beamforming Based Imaging Method for Early Breast Cancer Detection. Chinese Physics B, Volume 22(9), https://doi.org/10.1088/1674-1056/22/9/094101 